\title{
Victim-offender mediation and social work: focus groups with mediators in Flanders
}

\section{Introduction}

In several countries work with offenders, especially adult offenders, has been redefined in a sense that it is increasingly perceived as something other than social work (Smith, 2005). In England and Wales, for example, adult offenders are dealt with by probation services which are considered a distinct field from social work (Bauwens, 2009). In addition, youth delinquency is no longer considered to be social work's problem (Sharland, 2006). Consequently, social work seems to have abandoned (or have been exiled from) the criminal justice field (Burford \& Adams, 2004). A telling example of this withdrawal is the case of victim-offender mediation. As one of the most widely used expressions of restorative justice (Coates, Umbreit \& Vos, 2004), victim-offender mediation is, on the one hand, considered as an emerging area of international social work practice (Mantle \& Critchley, 2004), given its close link to social work's values of social justice, service, dignity and worth of the person, importance of human relationships, integrity and competence (van Wormer, 2009). On the other hand, however, we can remark that social work research is conspicuously absent in the field of restorative justice (Gumz \& Grant, (2009). Up till now research seems to be mainly conducted from judicial or criminological perspectives (Bradt \& Bouverne-De Bie, 2009b; Gumz, 2004). These studies either focus on the satisfaction of victims and offenders, the number of agreements signed, restitution completion and recidivism rates of offenders (Bradshaw \& Roseborough, 2005; Faget, 2008) or on the processes taking 
place between victims and offenders during the mediation such as power (Presser \& Hamilton, 2006), apology (Choi \& Severson, 2009) or the communication between victims and offenders (Tränkle, 2007). These studies, however, not only leave the role of social work in the restorative justice field unexplored (Gumz \& Grant, 2009), they also mainly focus on the individual level of victim-offender mediation, i.e. (the outcomes of) the communication process between victims and offenders. As we have argued elsewhere (Authors' own), though, a mere focus on the individual level makes victim-offender mediation - and hence the mediators involved with the implementation of it - vulnerable to become an instrument of the criminal justice system. If victimoffender mediation is perceived as a social work practice, attention should also be paid to the structural level, i.e. the social political dimension of victim-offender mediation in terms of challenging the criminal justice system and reflecting on how - if at all mediation contributes to this process.

Based on these insights, this article examines this social work dimension by reporting on the findings of two focus groups conducted with mediators working in juvenile and adult mediation practices in Flanders (the Dutch-speaking part of Belgium). This study was conducted as the final part of a $\mathrm{PhD}$ research in which a comparison was made between juvenile and adult mediation in Flanders. In this article, we analyse these focus groups with the aim of gaining more insight into how mediators themselves perceive their professional role and to what extent they refer to the individual and structural level of victim-offender mediation. Though a detailed comparison between juvenile and adult mediation is beyond the scope of this article, the fact that both mediators for juvenile and adult mediation participated in our research is interesting with regard to the scope of this article, as the relation between mediation and social work seems to be regarded 
more highly within juvenile justice than within the criminal justice system (Mantle \& Critchley, 2004). The Flemish mediation practice, then, is a particularly interesting case because even though juvenile and adult mediation are embedded in different legislations, they are both considered to be a practice carried out by professionals who work independently from the criminal justice system.

In the following part, we first define restorative justice and victim-offender mediation after which we briefly outline the main characteristics of juvenile and adult mediation in Flanders. Next, we outline the methodology of our study and present the main findings of our focus groups. To conclude, we discuss some implications for victim-offender mediation as a social work practice.

\section{Defining restorative justice}

Despite the burgeoning scholarly attention to restorative justice (Daly, 2004) there is still confusion as to the exact meaning of restorative justice (Gavrielides, 2007). However, there seems to be consensus that restorative justice 'offers a very different way of understanding and responding to crime' (Umbreit et al., 2005: 255). Instead of offending primarily being defined as a violation of the state's interests, restorative justice considers crime to be 'a violation of people and relationships' (Zehr, 1990, p. 181) and emphasises reparation for victims and integration of offenders into their communities (Hudson, 2006). Consequently, it opens doors to the effective participation of those who are normally denied a voice in traditional criminal justice (Crawford \& Clear, 2003: 215). 
The restorative justice umbrella shelters a range of practices, such as victim-offender mediation, community reparative boards, family group conferencing and circle sentencing (Bergseth \& Bouffard, 2007). In this article, we limit our focus to victimoffender mediation. Victim-offender mediation is a process designed to address the needs of victims while insuring that offenders are held accountable for their offending. A mediator assists two parties in arriving at an agreement that addresses the needs of both parties and provides a resolution to the conflict (United Nations Office on Drugs and Crime, 2006). Mediation can occur via a shuttle process in which the mediator acts as a go-between for both participants or through a face-to-face meeting. In Belgium, both juvenile and adult mediation were legalised through respectively the new Youth Act (June 2006) and the Act of 22 June 2005.

\section{Victim-offender mediation in Flanders}

Juvenile mediation started in Flanders in 1987 as a project aimed at first offenders, criticizing the protectionist framework of the Belgian youth protection law. This project is further developed throughout the 1990s in which juvenile offenders are no longer considered to be victims of society, but risks to society (Nagels, 2004) and a (restorative) youth sanction model is increasingly asked for. Since June 2006 Belgium has a new Youth Act legalising victim-offender mediation on the level of both the public prosecutor and the youth court. The Act prescribes that all public prosecutors in all cases in which a victim has been identified are obliged to consider the possibility of referring the case to a mediation service. The way juvenile mediation is fitted in this Act, however, has caused a shift in the meaning of juvenile mediation. Whereas in the 
original mediation project, mediation was considered a way to restore young people's competence to act, it is increasingly reduced to a method to enhance young people's sense of responsibility, and to hold juvenile offenders accountable to repair the damage they have caused to victims and society.

As we described elsewhere (Authors' own), this somehow differs from adult mediation that started as a project in 1993 as a criticism of the criminal justice system. Two elements seem to distinguish the adult mediation project from the juvenile mediation project. First, the adult mediation project developed from a victimological perspective. Rather than focusing on the offender, it emphasises the communication between victims and offenders (Willemsens, 2004) offering them 'a search for the possibility - literally and figuratively - to put things in place once again. It is about re-positioning [...] in relation to one's self and to others' (Foqué, 2005, p.197, italics in original). In other words, adult mediation is more about restoring people's ownership of the conflict (cf. Christie, 1997). Second, within the adult mediation project it was explicitly intended to 'deal exclusively with adult offenders and with crimes of a certain degree of seriousness. Only crimes for which the prosecutor had already decided to proceed were taken into consideration' (Aertsen \& Peters, 1998: 515-516). By going beyond diversion adult mediation not only focuses on the dialogue between victim and offender but also between the parties and the judge, and between all rationalities involved with the criminal justice system. Although the law of 22 June 2005 abandoned the criterion of seriousness of the offence, making mediation possible at all levels in the criminal procedure, we can remark that most of the offences are still serious crimes. 
Analysing the history of both mediation practices reveals important conceptual differences between both mediation practices. Whereas juvenile mediation is mainly focused on the responsibilisation of juvenile offenders, adult mediation is mainly concerned with critically challenging the way the criminal justice system deals with criminality. Moreover, a study of juvenile and adult mediation processes ${ }^{1}$ showed that this different conceptualisation of victim-offender mediation results in differences concerning the reach (property crimes versus personal crimes) and settlement of juvenile and adult mediation processes (more started and completed mediation processes and agreements within juvenile mediation than adult mediation).

\section{Methodology}

The abovementioned differences reveal a conceptual tension between a methodical/individual and a structural approach to victim-offender mediation. This finding raised the question whether this tension is also reflected in how mediators perceive their role within victim-offender mediation practices. Therefore, we decided to conduct two focus groups, one with mediators for juvenile mediation and one with mediators for adult mediation. By discussing these differences with the mediators, we aimed at gaining more insight into what mediators think about the position of victimoffender mediation and how they look at their role.

According to Vaughn and colleagues (1996), the goal of focus groups is to elicit participant's feelings, attitudes and perceptions about a selected topic. Group discussions allow gathering a lot of information in a short period of time, while the group interactions stimulate the richness and differences in meaning (Krueger \& Casey, 
2000). An important tool is the interview guide, which generally consists of very general open-ended questions, which can be modified in response to the discussion and interaction between the respondents (Stewart \& Shamdasani, 1998). Our interview schedule consisted of the following three main questions: (a) How do you look at the position of mediation between welfare and justice? (b) What similarities/differences do you distinguish between juvenile and adult mediation? (c) How do you understand/explain the differences in reach and settlement of juvenile and adult mediation processes?

In Flanders all 14 juvenile mediation services and all 14 adult mediation services received a letter inviting one mediator per service to participate in the focus group. With regard to juveniles 11 mediators complied with our request ( 8 females and 3 males, aged between 23 and 50 years old and at least 1 year experience as a mediator). Six mediators took part in the focus group for adult mediation ( 3 females and 3 males, aged between 24 and 44 years old with at least 1,5 year experience as a mediator). The focus groups were moderated by the researcher and co-moderated by the supervisor. Both focus groups were audio-taped and lasted two hours. A conventional content analysis (Hsieh \& Shannon, 2005) was applied to analyse the transcripts of the focus groups. The transcripts were read through, highlighting all text that referred to mediators' perception of their role and to the individual and/or structural dimensions of mediation. This process resulted in the identification of three main themes: the mediators' perception of (1) the position of mediation, (2) the role of mediators and (3) the structural level of mediation. In the next part, we present the findings of the focus groups. 


\section{Findings}

In the following we present our main findings. To underpin these findings, we have added quotations from the focus group with mediators for adult mediation (AM) and juvenile mediation (JM).

\section{The position of mediation: balancing between welfare and justice}

The way mediators think about their role is connected to their perception of the position of victim-offender mediation. As a practice that intervenes in situations in which people are confronted with crime, victim-offender mediation positions itself at the intersection between justice and welfare. It is neither merely justice as mediation is a voluntary process, nor is it merely welfare as the mediators obtain their mandate from the criminal justice system. Or as one of the mediators puts it:

'We are no social workers, but we are not judicial counsellors either.' (AM)

This position implies that in their daily work mediators are confronted with a tension between offering care to the victims/offenders and the fact that they work in cases that go through a judicial procedure which implies that their work can have (or has) an influence on the judicial settlement of the crime. The mediators for adult mediation hereby indicate that they generally start from care for their clients and care for the communication process between victim and offenders. However, the clients themselves and/or the inflow of the cases can shift this towards a focus on the procedural settlement rather than on the communication on the conflict.

'There are people who are mainly focused on the emotional coping with the crime and are in no way or at no moment concerned with the question whether there should be some feedback to the judge or not.' (AM) 
'Yeah, and also the nature of the cases. Property crimes will also be more about judicial aspects than personal crimes.' (AM)

On the other hand, it was argued that the legal framework also has an important influence on their work.

'On the other hand, I think that we also strongly use that judicial [framework], I mean from the age of 18, you are dealt with by the criminal justice system. We often have that kind of files with our colleagues of juvenile mediation. The juvenile is 17 years and 11 months and the adult is 18 years and 1 month. They are both equally developed, as a matter of speaking, but still they are dealt with in a very different manner and actually as a mediator you have to respect that.' (AM)

Especially, the mediators for juvenile mediation seem to refer more to the legal framework within which they provide care to the participants.

'Indeed, we receive our task from the public prosecutor or from the youth court, so it is also about the judicial.' (JM)

Therefore, their attention to care is limited to what is necessary to enable people to find a solution for the crime, even though several mediators indicate that this is complicated. 'If you come in people's houses, it is important not to fall into the pitfall of taking care for everything and to make commitments.' (JM)

'But that is just a very difficult line, which you must be aware of as a person.' (JM)

It seems thus that the way mediators look at the position of victim-offender mediation is influenced by the legal framework in which they work. Apart from this, both groups of mediators indicate that their focus is also influenced by the personal style and/or professional background of the mediator. Some mediators pay more attention to care, whilst others are more concerned with reaching an agreement to send to the judge or public prosecutor. 
'I think that within the group of mediators you have people on a continuum from more listening, careful to very outcome-oriented.' (JM)

'But, you can remark that there are differences in emphasis depending on the mediator. For instance, someone who is really focused on giving feedback to the judicial actors, will also discuss this sooner and more frequently with their parties. Whereas others believe that the parties themselves should determine the tempo and the content of the mediation process.' (AM)

\section{The role of the mediator}

The influence of the legal framework on how mediators think about the position of mediation seems to be reflected in how they perceive their role. Mediators for juvenile mediation seem to orientate mediation more towards working at the consequences of the crime and towards finding ways for offenders to take responsibility for these consequences. This focus on finding a solution also implies a greater orientation of mediators for juvenile mediation towards reaching a written agreement, though some mediators have another opinion about this.

'At the beginning [of the focus group] we talked about the outcome of mediation, but in my opinion, the aim of mediation is not to reach an agreement, that's not what I'm satisfied most with in mediation.' (JM)

Mediators for adult mediation, on the other hand, seem to focus more on the task of creating the conditions to enable communication between victims and offenders, including the question of how much attention should be paid to realise these conditions. 'It is always a search for finding your position as a mediator. Should I create conditions that bring in a certain expertise or a certain support? Or can I do it myself and are people happy about this?' (AM) 
One of these conditions is informing victims and offenders so that they can understand what victim-offender mediation is all about. The mediators for adult mediation feel that they have an important role in ensuring that victims and offenders can make a thoughtout decision whether to participate or not.

'I think in the first place it is our task to explain our client - whatever his capabilities might be - what mediation could actually mean to him' [...] And if you are convinced of that, then you wait and see what happens, I think.' (AM)

In both focus groups it was emphasised that mediators play an important role as they have an influence on how victims and offenders are approached. Especially, the mediators for adult mediation stress that the way in which they address victims and offenders might influence their willingness to participate in mediation.

'I think that the way mediation is offered to the parties determines to a large extent whether they participate or not.' (AM)

Some mediators doubt if sending a letter allows victims and offenders to make a thought-out decision to participate, especially if these are standard letters. Writing a standard letter is a procedure which guarantees that everybody is approached in a uniform manner. It does not, however, take into account the diversity in contexts of offenders and victims. Some mediators admit that they deviate from this procedure whenever it is possible and/or appropriate.

'I mean, it is different when you have to write a letter to someone who is victim of a rape than to someone who's car got scratched. [...] I always think about how I will address people.' (AM)

The mediators point out that they are aware that their way of approaching people inevitably excludes certain victims and offenders. At the same time, however, the 
mediators indicate that they only have limited knowledge about whom does not respond to the offer of mediation and why.

\section{The structural level of victim-offender mediation}

As we already mentioned, the focus groups reveal that mediators think that there are important differences between the contexts in which mediators for juvenile and adult mediation have to work. They especially refer to the distinct procedure of juvenile and adult mediation, and its influence on the inflow of the cases. Whereas in adult mediation, the initiative to mediate lies with the parties themselves, in juvenile mediation it is the public prosecutor who must consider offering mediation in every offence that meets the criteria. As a consequence, the mediators feel that the public prosecutors play a more influential role - whether genuinely or not - in juvenile mediation than in adult mediation.

'I also think that the youth public prosecutors are much more 'present'" - 'that's because their decision to prosecute or not depends on it.' (AM)

'I think that there are too many files in which the offender and his parents participate because they feel obliged to do so, no matter how hard you stress that it is voluntary.' $(\mathrm{JM})$

The mediators, however, do not think that these differences influence their work, in terms of the way they are dealing with victims and offenders during the mediation process.

'I think we do mediations in the same way. I do not think that there are differences in that.' (JM)

'Still, I feel that they [mediators in juvenile mediation] are dealing with these mediation processes in the same way.' (AM) 
On the one hand, these quotations indicate that mediators are mainly focused on the individual dimension of mediation as they refer to the method of mediation ('we all do the same'). On the other hand, however, the focus groups revealed that mediators do not perceive their role as merely mediating between victims and offenders. In the focus group with mediators for adult mediation, for example, the mediators referred to a debate amongst them concerning the question of what constitutes the essence of their practice: the method of mediation or the restorative debate. For some mediators, focusing on the method makes them vulnerable to become an instrument of the criminal justice system.

'But we should not merely focus on our files, because then we are actually allowing ourselves to be instrumentalised as some kind of settlement.' (AM)

Also the mediators for juvenile mediation seem to be concerned with the societal messages mediation expresses. They indicate that sometimes mediation results in compensation for the victim, whereas these files would have been dismissed had mediation not existed (e.g. files concerning thefts of bicycles). For some mediators, this is precisely one of the important values of mediation, as it offers an opportunity to show that every offence is taken seriously. Others, however, doubt if mediation, when it concerns such minor offences, has an added-value compared to a compensation settlement. It is not that they question that victims should be compensated, but according to them, these files are not what mediation is all about.

'Ok, but I do get the meaninglessness to mediate with a school principal and 5 pupils attending that school and that the principal says 'Ok, I agree with the mediation. I want to talk to these boys and they have to clean the playground on Wednesday afternoon'. Then I think to myself, what am I doing here?' (JM) 
'But it's not because society thinks that this should be settled, that we should do this. [...] Because, indeed, some files have nothing to do with the reasons why victimoffender mediation was developed. I do think that the damage should be restored, but I am not sure if this is something that our services should do.' (JM)

Moreover, some mediators for juvenile mediation wonder whether mediation contributes to an increased criminalisation of problems, denying rather than addressing people's responsibility.

'It's like they need a mediator to solve something that they should be able to do themselves and we talk about giving responsibility back to the people, giving the conflict back to the people...' (JM)

\section{Discussion}

As outlined in the introduction, this article focused on mediation as a social work practice by gaining more insight into how mediators themselves perceive their professional role and to what extent they refer to the individual and structural dimensions of victim-offender mediation. The focus groups show an important tension in relation to mediators' role in victim-offender mediation. Do mediators only have to focus on the method of mediating (the individual dimension) or do they also have to engage in the restorative debate (the structural dimension)?

On the one hand, the focus groups reveal that the mediators are concerned with the structural dimension of mediation as they do not perceive themselves as merely administrators of the criminal justice system. This can be observed, for example, in the mediators' doubt whether they contribute to an increased criminalisation of social problems or in their concern with the question how to realise the best conditions under which people are able/willing to respond to the offer of mediation. 
On the other hand, though, the fact that the mediators believe that they all do the same indicates that mediators are not fully aware that their perception of their role seems to be influenced by the context in which they work. In this perspective, it is remarkable that the mediators for juvenile mediation strongly describe their task as finding ways for offenders to take responsibility for the consequences of their crime, which resembles the strong focus of the Youth Act of 2006 on the responsibility of the juvenile offender. The mediators for adult mediation are more concerned with questions about realising the conditions under which people can respond to the offer of mediation, which seems to be in accordance with the underlying concept of adult mediation that stresses the 'ownership' of people. Moreover, the mediators indicate that they only have little knowledge about who does or does not respond to the offer of mediation and why people decide to participate or not. This shows that only little attention is paid to the question of how mediators and/or the offer of mediation itself influences the accessibility of mediation services, as well as to the question of hidden exclusion mechanisms within the mediation practice. These are, however, important questions to be raised as it has been argued that 'larger inequalities in society are likely to be reproduced within the framework of restorative justice' (cf. Levrant et al., 1999: 16). If we want victim-offender mediation to be a social work practice that meets its value of social justice (cf. Code of Ethics, NASW), the tension showed by the focus groups is an important challenge for mediation services. This implies that future social work research should not only focus on the method of mediation, but should support mediators in recognising and critically engaging with their political task.

\section{Note}


1. This study was conducted by the first author as second part of her $\mathrm{PhD}$ research and concerned 703 juvenile mediation processes and 669 adult mediation processes which were closed between 1 January 2007 and 31 March 2007.

\section{References}

Aertsen, I. and T. Peters (1998) 'Mediation and Restorative Justice in Belgium', European Journal on Criminal Policy and Research 6(4): 507-25.

Authors' own

Bauwens, A. (2009) 'Probation Officers' Perspectives on Recent Belgian Changes in The Probation Service', Probation Journal 56(3): 257-268.

Bergseth, K.J. and J.A. Bouffard (2007) 'The Long-Term Impact of Restorative Justice Programming for Juvenile Offenders', Journal of Criminal Justice 35: 433-451.

Bradshaw, W. and D. Roseborough (2005) 'Restorative Justice Dialogue: The Impact of Mediation and Conferencing on Juvenile Recidivism', Federal Probation 69(2): $15-21$.

Bradt, L. and M. Bouverne-De Bie (2009b) 'Social Work and the Shift from 'Welfare' to 'Justice', British Journal of Social Work 39(1): 113-27.

Burford, G. and P. Adams (2004) 'Restorative Justice, Responsive Regulation and Social Work', Journal of Sociology and Social Welfare 31(1): 7-26.

Choi, J.J. and M. Severson (2009) 'What! What kind of apology is this?: The nature of apology in victim-offender mediation', Children and Youth Services Review, 31(7): 813-821.

Christie, N. (1997) ‘Conflicts as Property', British Journal of Criminology 17(1): 1-15. 
Coates, R.B., M.S. Umbreit and B. Vos (2004) 'Restorative Justice Systemic Change: The Washington County Experience', Federal Probation 68(3): 16-23.

Crawford, A. and T.R. Clear (2003) 'Community Justice: Transforming Communities Through Restorative Justice?', in E. McLaughlin, R. Ferguson, G. Hughes and L. Westmarland (eds) Restorative Justice: Critical Issues, pp. 215-228. London: Sage Publications Ltd.

Daly, K. (2004) 'Pile It on - More Texts on RJ', Theoretical Criminology 8(4): 499507.

Faget, J. (2008) 'Epistemological reflections on the evaluation of restorative justice practices', British Journal of Community Justice, 6(2): 77-83.

Foqué, R. (2005) 'Punishment, Restorative Justice, and The Morality of Law: Concluding Observations', in E. Claes, R. Foqué and T. Peters (eds) Punishment, Restorative Justice and The Morality of Law, pp. 183-198. Antwerp: Intersentia.

Gavrielides, T. (2007) 'Restorative justice theory and practice: addressing the discrepancy'. Helsinki: Academic Bookstore.

Gumz, E.J. (2004) 'American Social Work, Corrections and Restorative Justice: An Appraisal', International Journal of Offender Therapy and Comparative Criminology 48(4): pp. 449-460.

Gumz, E.J. and C.L. Grant (2009) 'Restorative Justice: A Systematic Review of The Social Work Literature', Families in Society 90(1): 119-126.

Hsieh, H.-F. and S.E. Shannon (2005) 'Three approaches to qualitative content analysis', Qualitative Health Research, 15(9): 1277-1288.

Hudson, B. (2006) 'Balancing The Ethical and The Political: Normative Reflections on The Institutionalization of Restorative Justice', in I. Aertsen, T. Daems and L. 
Robert (eds) Institutionalizing Restorative Justice, pp. 261-281. Cullompton: Willan Publishing.

Krueger, R.A. and M.A. Casey (2000) Focus groups, a practical guide for applied research. Thousand Oaks, CA: Sage.

Levrant, S., F.T. Cullen, B. Fulton and J. Wozniak (1999) 'Reconsidering Restorative Justice: The Corruption of Benevolence Revisited?', Crime \& Delinquency 45(1): $3-27$.

Mantle, G. and A. Critchley (2004) 'Social work and child-centered family court mediation', British Journal of Social Work, 34(8): 1161-1172.

Nagels, C. (2004) Jeunes, violence et société. Analyse du discours de la Chambre des représentants de 1981 à 1999 dans une perspective de criminologique critique. Doctoral thesis. Centres de recherches criminologiques de U.L.B.

Presser, L. and C.A. Hamilton (2006) 'The micropolitics of victim-offender mediation', Sociological Inquiry, 76(3): 316-342.

Sharland, E. (2006) 'Young People, Risk Taking and Risk Making: Some Thoughts for Social Work', British Journal of Social Work 36(2): 247-265.

Smith, D. (2005) 'Probation and Social Work', British Journal of Social Work 35: 621637.

Stewart, D.W. and P.N. Shamdasani (1998) 'Focus Group Research. Exploration and Discovery', in L. Bickman and D.J. Rog (eds) Handbook of Applied Social Research Methods, pp. 505-26. Thousand Oaks: Sage Publications.

Trankle, S. (2007) 'In the shadow of penal law - Victim-offender mediation in Germany and France', Punishment \& Society, 9(4): 395-415. 
Umbreit, M. S., B. Vos, R.B. Coates and E. Lightfoot (2005). Restorative Justice in The Twenty-First Century: A Social Movement Full of Opportunities and Pitfalls', Marquette Law Review 89(2): 251-304.

United Nations Office on Drugs and Crime (2006). The Handbook on Restorative Justice Programmes. New York.

van Wormer, K. (2009) 'Restorative Justice as Social Justice for Victims of Gendered Violence: A Standpoint Feminist Perspective', Social Work 54(2): 107-116.

Vaughn, S., J.S. Schumm and J. Sinagub (1996) Focus Group Interviews in Education and Psychology. London: Sage Publications.

Willemsens, J. (2004) 'Belgium', in D. Miers and J. Willemsens (eds) Mapping Restorative Justice. Developments in 25 European Countries, pp. 23-36. Leuven: European Forum for Victim-Offender Mediation and Restorative Justice v.z.w.

Zehr, H. (1990) Changing Lenses: A New Focus for Crime and Justice. Scottsdale: Herald Press. 